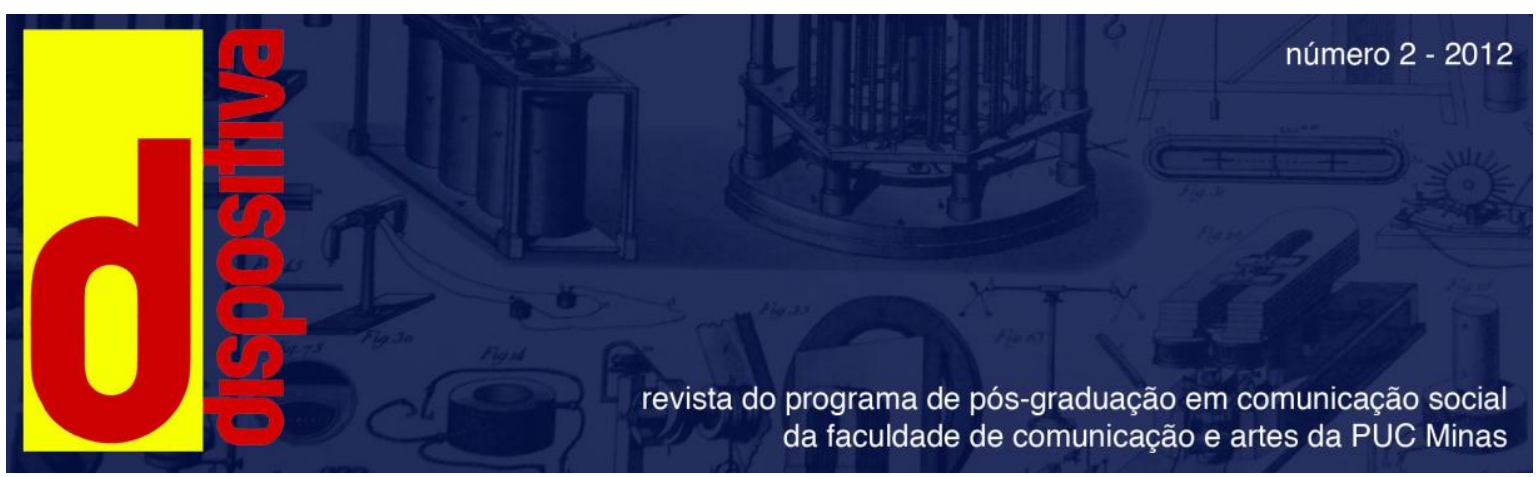

\title{
House MD e as matrizes do gênero policial// House MD and the matrices of the policial gender
}

\author{
Glória MFI Gomide ${ }^{1}$
}

\begin{abstract}
Resumo
Este trabalho analisa o seriado House MD, que teve oito temporadas, com o seu último episódio exibido em maio de 2012. O desenvolvimento de cada episódio é a cadeia de deduções sobre o que pode ter causado a doença do paciente e como deve ser tratada. House é um decifrador de enigmas, que acredita que "todos os homens mentem", por isso só lhe interessam os sintomas. O paciente é só o objeto de estudo, cujo diagnóstico deverá ser desvendado como se desvenda um crime. É o entretenimento, tomando emprestado o modelo da investigação científica. Este trabalho demonstra a valorização dos seriados e fundamentalmente de House MD, que tem sua gênese nos policiais clássicos, como os de Poe e Doyle e cujos roteiros são baseados nas teorias literárias de Todorov e Narcejac.
\end{abstract}

Palavras-chave: House MD; seriados; narrativas policiais.

\begin{abstract}
This work analyses the serial House MD, which had eight seasons, with its last episode aired in May 2012. The development of each episode is the chain of deductions about what may have caused the disease of the patient and how it should be treated. House is a puzzle descrambler, who believes that "all men lie", that is why just interests him the symptoms. The patient is only the object of study, whose diagnosis must be unraveled as if a crimes unveiled. It is the entertainment borrowing the model of scientific research. This work demonstrates an appreciation of the serials and fundamentally of House MD., which has its genesis in the classic police, as Poe and Doyle and whose literary roadmaps are based on Todorov and Narcejac's theories.
\end{abstract}

Keywords: House MD; TV series; detective stories.

O cineasta canadense David Cronenberg, em Os grandes diretores de cinema, (Tirard, 2002) conta que sempre considerou a literatura como uma arte superior ao cinema. No entanto, ao se encontrar com Salman Rushdie, um dos maiores escritores

\footnotetext{
${ }^{1}$ Publicitária, doutora em Literatura e professora titular da Faculdade de Comunicação e Artes da PUC Minas.
} 
contemporâneos, este lhe disse que achava exatamente o contrário e que, inclusive, estaria disposto a tudo para fazer um filme. "E no fim das contas, concordamos que as linguagens do cinema e da literatura se completam, e até mesmo se alimentam uma da outra. É impossível julgar uma em relação à outra.” (TIRARD, 2002, p.195).

Assim como existe esta linguagem cinematográfica, vimos surgir em meados do século XX outra linguagem, derivada de imagens - a televisiva. E se um grande cineasta teve preconceitos, sentindo-se um autor menor frente a um autor literário, o mesmo acontece com a televisão e sua produção frente ao cinema e junto a ela própria.

A televisão foi durante anos vista apenas como um fenômeno de massa, transmissora de produtos de baixa qualidade. No entanto, na década de 1950, a mais conceituada revista de cinema, Cahiers du cinéma, trazia o subtítulo: Revue de cinéma et du télécinéma, o que pode ser compreendido como valorização e seriedade da tela pequena desde aquela época (MACHADO, 2002, p.23). Não há unanimidade sobre a qualidade da linguagem televisiva, como não há sintonia entre os teóricos, tema de discussão desde a sua origem. Mas se há uma gama de programação de baixa qualidade, há na televisão atual um tipo de programação que prima pela alta qualidade, como, por exemplo, o seriado norte-americano.

Misto de linguagem televisiva e cinematográfica, estes seriados atualmente têm público cativo e são produções cuidadosas que exigem um trabalho de pesquisa rigoroso dos roteiristas - categoria cada vez mais privilegiada, diretores e elenco. Os enredos, assim como nas produções cinematográficas, muitas vezes são alimentados por obras literárias.

A série House $M D$ é um bom exemplo deste tipo de seriado e são notórias suas origens nas narrativas policiais, escritas por Edgar Allan Poe e Arthur Conan Doyle. Ironicamente, essas narrativas também foram jogadas no limbo da baixa literatura, sendo valorizadas apenas a partir da segunda metade do século XX, por intelectuais e escritores como Jorge Luis Borges, Bioy Casares, Otto Maria Carpeaux, Umberto Eco, Tzvetan Todorov, pelo menos.

Conforme Edgar Allan Poe, na maioria das histórias policiais que se preza, os roteiros são sempre escritos de trás para frente, para que os incidentes convirjam para o fim desejado. Essa é a sua teoria, descrita n'A filosofia da composição, - um tratado essencial para a elaboração de uma história policial, texto destinado a destrinchar sua criação $O$ corvo, publicado anonimamente no Evening Mirror e, pelo sucesso obtido, republicado 
com o nome do autor, um mês depois. A filosofia da composição é um tratado essencial para a elaboração de uma história policial.

Nada é mais claro do que deverem todas as intrigas, dignas desse nome, ser elaboradas em relação ao epílogo antes que se tente qualquer coisa com a pena. Só tendo o epílogo constantemente em vista poderemos dar a um enredo seu aspecto indispensável de conseqüência, ou causalidade, fazendo com que os incidentes e, especialmente, o tom da obra tendam para o desenvolvimento de sua intenção. (POE, 1997, p.911)

Este ensaio de 1846, publicado no Graham's Lady's and Gentleman's Magazine serve como uma luva para os roteiristas da série House MD.

Como lemos em Poe, no seu conto Os crimes da Rua Morgue (POE, 1997, p. 6591), o assassino é um orangotango. A partir desta solução insólita são arranjados todos os detalhes da história: a janelinha alta e trancada, o condutor de para-raios, a carnificina. Se não houvesse este animal, todo o cenário seria inútil, já que a explicação final comanda a encenação.

Toda obra literária é um trajeto entre começo e conclusão, mas Poe parte da conclusão e remonta/retorna ao começo eliminando detalhes fortuitos, logo inúteis. Isto é, a lógica só pode intervir na gênese da obra a partir do momento em que se dá o epílogo. E só aí estaremos em condições de juntar, ou melhor, construir as outras partes, escolhendo as que se mantêm entre si, articulando-as de modo necessário. É a lapidação da história bruta, escrita pelo avesso, sendo burilada.

Só assim vemos aparecer a relação entre enigma e investigação. E, numa visão metaliterária, percebemos que a valorização do rigor lógico não é aplicada por Poe apenas no método de investigação de Charles Dupin - seu clássico detetive, mas também no próprio ato de construção textual.

Em suma, podemos perceber que o método descrito em A filosofia da composição é aquele em que o autor vai do enigma à construção da dedução, da ideia à imagem. Talvez, essa racionalidade aplicada à carpintaria literária seja hoje em dia lugar comum, mas, na época em que foi exposta, era de uma ousadia inquietante. E, atualmente, foi representada muito bem nos bastidores da roteirização de House MD.

O método utilizado por House é também equivalente a uma incursão à teoria semiótica, a qual ironicamente tem sua origem na história da medicina, e segue através dos séculos como uma licença à investigação. 


\begin{abstract}
A semiótica propriamente dita encontra seu ancestral mais antigo na história da medicina, aí entendida como o primeiro estudo diagnóstico dos signos das doenças. O médico grego Galeno de Pérgamo (139-199), por exemplo, referiu-se à diagnóstica como sendo "a parte semiótica" (semeiotikón meros) da medicina. No século XVIII a literatura médica também começou a empregar o termo sem(e)iologia como alternativa semiótica, às vezes, com algumas variações de sentido. Naquela altura, a semiótica médica foi ampliada para incluir três ramos de investigação: a anamnéstica, estudo da história médica do paciente; a diagnóstica, estudo dos sintomas atuais das doenças; e a prognóstica, que trata das predições e projeções do desenvolvimento futuro das doenças. (NÖTH, 2003)
\end{abstract}

House $M D$ é uma série médica, criada pelo produtor e escritor canadense David Shore, exibida nos Estados Unidos pela Fox e transmitida no Brasil pela TV fechada, através do Universal Channel. Ganhadora de vários prêmios foi um dos seriados mais vistos no mundo. Dividida em oito temporadas, teve seu término em maio de 2012.

O britânico Hugh Laurie é o protagonista, no papel do médico infectologista e nefrologista Dr. Gregory House, portador de uma dor física crônica, resultado de uma cirurgia que lhe afetou o músculo da perna. Tem como companheiros uma bengala e o mau humor. Idiossincrático, antissocial, fleumático, irascível, crítico, iconoclasta, ateu, arrogante, irônico, pretensioso, viciado em analgésicos - para não dizer mais alguns adjetivos negativos - é o responsável pelo Departamento de Diagnóstico do Hospital Escola Pricenton-Plainsboro, em Nova Jérsei, Estados Unidos, e especialista em descobrir diagnósticos em casos em que outros médicos falharam. House prefere não interagir com os pacientes, já que "todo homem mente" e usa sua equipe pra fazer a ponte entre ele e o doente. Trabalha através da descrição dos sintomas, e por meio de uma sucessão de erros, experimentos e acertos - discutidos com seus assessores, sempre chega à solução final correta.

Tem como amigo, o Dr. James Watson (Robert Sean Leonard), oncologista e interlocutor principal e como objeto de desejo sua chefe - durante sete das oito temporadas, a reitora do Hospital, Dr ${ }^{\mathrm{a}}$ Lisa Cuddy (Lisa Edelstein), especialista em endocrinologia. A equipe original, até a terceira temporada, era formada pela imunologista, Dr $^{\mathrm{a}}$ Allison Cameron (Jennifer Morrison), pelo neurologista, Dr. Eric Foreman (Omar Epps) e pelo especialista em tratamentos intensivos, Dr. Robert Chase (Jesse Spencer). A partir da quarta, novos médicos foram acrescidos, enquanto os primeiros se colocavam em outros cargos estratégicos - o cirurgião plástico, Dr. Chris Taub (Peter Jacobson), a Dr ${ }^{\mathrm{a}}$ Remy Hadley (Olivia Wilde), ou "13", como House a denomina, e o Dr. Lawrence Kutner (Karl Penn), especialista em medicina esportiva. Este ator, no entanto, foi convidado a trabalhar 
com o presidente norte-americano Barack Obama, logo que este assumiu a Casa Branca e teve a participação abortada no vigésimo episódio da quinta temporada, na qual ele se suicida misteriosamente. O episódio, inclusive teve o roteiro adaptado para o tema da morte induzida e a impossibilidade de descobertas.

Nas temporadas seguintes, outros médicos fizeram parte da equipe do Dr. House, sendo que na última, a oitava, duas novas personagens são incorporadas - a $\operatorname{Dr}^{\mathrm{a}}$ Jessica Adams (Odette Annable) e a Dr ${ }^{\mathrm{a}}$ Chi Park (Charlyne Yi), enquanto a $\operatorname{Dr}^{\mathrm{a}}$ Lisa Cuddy sai definitivamente e outras retornam. Mas, com certeza, a variação na equipe do Dr. House sempre trabalhou pela decifração do enigma, na solução do diagnóstico e em nenhum momento houve discrepâncias nas narrativas episódicas.

Muito se tem escrito sobre House, principalmente em literaturas de senso comum, como em, por exemplo, A ciência médica de House (HOLTZ, 2008), na qual o autor critica a estrutura de funcionamento da equipe, os tratamentos, a falta de ética e descuido da série, e usa vários argumentos médicos para provar que o seriado não é tão verossímil quanto parece, e que é impossível não ouvir o paciente real para a descoberta de seu diagnóstico.

Como ocorre com tantos aspectos da medicina, a técnica não consiste em meramente ler sinais e sintomas biológicos, mas compreender o paciente como pessoa. O médico simplesmente não junta os sintomas; ele deve pesar as informações, julgar sua precisão, suspeitar o que pode estar faltando e decidir sua relevância para a necessidade imediata do paciente. (HOLTZ, 2008, p.22)

No entanto, Holtz confirma a capacidade de atração da série, mesmo questionando a capacidade do anti-herói.

\footnotetext{
Um renegado médico brilhante, como o Dr. House, que marcha sobre a burocracia e a convenção médica em sua batalha individual para salvar seus pacientes é muito mais interessante do que os metódicos médicos que seguem as diretrizes e os procedimentos mais recentes, tentando não causar mais mal do que bem com seus testes e tratamentos. (...) E se um dia precisar ser hospitalizado, com sua vida em jogo, que tipo de médico você realmente vai querer que esteja no controle de seu caso? (HOLTZ, 2008, p.263)
}

Outra obra, novamente pseudocientífica, House e a filosofia - todo mundo mente (IRWIN; JACOBY, 2009), trata o seriado sob vários pontos de vista filosóficos - de Aristóteles ao Zen, provando a capacidade dedutiva correta do médico. O livro é dividido em capítulos nos quais o seriado é discutido sob o ponto de vista de temas como teologia, existencialismo, lógica, literatura policial, drogas, virtudes, caráter, semiótica, tudo de uma maneira bem-humorada. 
Assim como Sócrates e Sherlock Holmes, House intriga-se com enigmas. Seu desejo obstinado, inflexível pela verdade, combinado com suas extraordinárias habilidades de raciocínio, significa que os enigmas são de fato resolvidos enquanto vidas são salvas. Falando de raciocínio e verdade, House tem muito a dizer sobre a própria filosofia. Para House, a navalha de Occam significa que a explicação mais simples é que quase sempre alguém fez alguma besteira. E quanto à realidade? Os filósofos discutem muito esta questão. House diz que a realidade está sempre errada. E o método socrático? Ele o adora. Diz que é a melhor maneira que temos para ensinar qualquer coisa que não seja fazer malabarismos com serras elétricas. (IRWIN; JACOBY, 2009, p.14).

Na internet há uma série de websites, blogs, que tratam House MD como uma febre contagiosa: seus provedores são todos fanáticos viciados pelo médico sarcástico. Há inclusive profissionais se apresentando como "O House brasileiro", como o médico Salmo Raskin $^{2}$.

Conforme Arlindo Machado, em A televisão levada a sério (MACHADO, 2000) há vários tipos de narrativas seriadas televisivas - a teleológica, na qual se vê uma única narrativa (ou outras entrelaçadas e paralelas) que se desenvolve linearmente até o final da temporada com o final resolvido nos últimos capítulos; a narrativa autônoma, com início, meio e fim e na qual cada episódio se fecha em si mesmo, mantendo, no entanto, as mesmas personagens e o terceiro tipo em que se mantém apenas a temática, com outras personagens e situações diferentes.

Por outro lado, existem seriados em que malgrado se possa verificar uma estrutura básica de episódios independentes, permitindo, portanto, que possam ser assistidos em qualquer número ou ordem, há uma situação teleológica, um início que explica as razões do(s) conflito(s) e uma espécie de objetivo final que orienta a evolução da narrativa. (MACHADO, 2000, p.85).

O caso House MD cabe nesta última categoria - houve um episódio piloto para apresentação das personagens e, apesar de os episódios poderem ser assistidos isoladamente, perde-se na situação básica: o desenvolvimento da história do Dr. House e sua equipe.

Para o espectador ocasional há um alento, pois em cada episódio há uma situação de suspense, um caso a ser resolvido que se fecha em si. Mesmo necessitando de um conhecimento prévio, é confortável acompanhar um seriado.

\footnotetext{
${ }^{2}$ www.genetika.com.br/midia/entrevista_vivasaude 
$\mathrm{Na}$ série, o leitor acredita que desfruta da novidade da história enquanto, de fato, distrai-se seguindo um esquema narrativo constante e fica satisfeito ao encontrar um personagem conhecido, com seus tiques, suas frases feitas, suas técnicas para solucionar problemas... A série neste sentido responde à necessidade infantil, mas nem por isso doentia, de ouvir sempre a mesma história, de consolar-se com o retorno do idêntico, superficialmente mascarado. (ECO, 1989, p.123).

O plot de cada episódio é a tentativa de descobrir o diagnóstico que levou o paciente a House. Paralelamente há o desenvolvimento das relações entre as personagens principais, com seus conflitos particulares, necessários para o esclarecimento das personalidades e, por último, um caso extemporâneo, normalmente outro paciente com uma doença comum atendido no Pronto Socorro do Pricenton-Plainsboro. Todo este enredo se entrelaça para se levar ao insight do desvendamento do diagnóstico da históriamãe.

Os roteiristas de House MD são assessorados por quatro médicos - Lisa Sanders, John Sotos, Harley Liker e David Foster, o único também roteirista, fundamentais para dar verossimilhança ao caso médico e seguem exatamente as normas de Allan Poe. O roteirista escreve, por exemplo, uma história em que seu paciente deve ser diagnosticado como deficiente neurológico, o que lhe causa alterações cardíacas. No entanto, precisa saber quais são essas doenças e como deve ser o desenrolar do caso. O papel dos consultores é criar uma situação possível e levantar várias hipóteses para que a história se encaixe. $\mathrm{O}$ trabalho do detetive House é, antes de tudo, um trabalho de decifração de sinais, uma busca de um significado mais amplo para os indícios - os sintomas, que se apresentam como promessas de um texto que é necessário compor, para, em seguida, ser reescrito. Puro Poe.

Tzvetan Todorov parte do romance clássico policial, o de enigma, e vai além. Para ele, todo romance policial de enigma consiste de duas histórias.

Tout roman policier est bâti sur deux meurtres, dont le premier, commis par l'assassin, n'est que l'occasion du second dans lequel est la victime du meurtrier pur et impunissable du dectétive, [et que] le récit... superpose deux séries temporalles; les jours de l'ênquete qui commencent au crime, et les jours du drame qui mènent à lui. (TODOROV, 1978, p.11)

Se voltarmos a Edgar Allan Poe, veremos que tanto o trabalho de Charles Dupin em relação aos crimes em questão, quanto a narração de suas deduções são posteriores ao fato consumado, o que só acontece depois de o crime ter ocorrido.

O mesmo podemos dizer sobre a série House MD. Chega a ele, House, um indivíduo com uma doença desconhecida, não decifrada por outros médicos e o 
desenvolvimento da história é a cadeia de deduções sobre o que pode ter causado a doença e como deve ser tratada. Para isso é vasculhada sua vida pessoal, sua casa é invadida, seu passado pesquisado para se chegar ao diagnóstico correto. A cada episódio um sintoma desencadeia um turbilhão de hipóteses para se chegar à solução correta. Como na teoria de Todorov, a doença já existe antes de a história começar e o roteiro levará a 43 minutos de investigação. Assim o puzzle é totalmente completado.

Na narrativa policial o vilão é o criminoso, em House MD é a doença - qual é, o que pode tê-la causado, e o que fazer para exterminá-la. O enigma, ou doença, é o que sustenta cada episódio. O seriado é, pois, uma pseudonarrativa policial e por isso podemos seguir pistas que autores escreveram sobre o gênero.

Thomas Narcejac aponta quatro normas - que chama de leis - para uma boa narrativa policial, as quais, em suma, determinam que o romance policial deve ser lido, construído e escrito como um romance. Neste caso, leia-se como um bom roteiro:

\footnotetext{
$1^{\circ}$ Debe haber entre el miedo y el razonamiento, un equilibrio de tal forma dosificado que a un máximo de espanto corresponda siempre un máximo de sencillez lógica.

$2^{\circ}$ El héroe de la aventura no solamente debe ser simpático, sino también imponerse al lector de tal forma que éste delegue en él la tarea de pensar. (Nunca me cansaré de repetir que la novela policíaca debe leerse igual que otra novela cualquiera.)

$3^{\circ}$ Es preciso que los enigmas propuestos al detective sean al mismo tiempo difíciles pruebas de su capacidad. (Dicho de otra forma: la novela policíaca se construirá como una novela)

$4^{\circ} \mathrm{El}$ estilo de la novela policíaca deberá valorar situaciones dramáticas. (Dicho de otra forma: la novela policíaca se escribirá como una novela) (NARCEJAC, 1982, p.70).
}

São essas as regras que Charles Dupin, detetive criado por Edgar Allan Poe, segue. Seu método é hipotético-dedutivo, assim como o do Dr. House. Começa seu raciocínio com uma teoria provisória (hipótese), que permite voltar aos fatos e ver se o método explica-os. Se restarem ainda fatos inexplicáveis, faz-se uma revisão, e outra, se necessário, até que haja o ajuste completo dos acontecimentos: do fato como ele se deu, dos sintomas que se apresentaram. A investigação é encerrada com o criminoso ou doença desmascarada. Esse método, o método do detetive ou método do médico de diagnóstico de uma personagem criada ulteriormente, quando o autor está de posse de todos os 
elementos da narrativa -, faz o percurso contrário do romancista ou roteirista que compõe a história. Ele verifica o engenho da intriga.

Através da persona do detetive, médico de diagnósticos, os roteiristas e seus consultores dão a si mesmos a prova de que usaram bons índices. $\mathrm{O}$ médico-detetive não erra no final, porque, se errar ou se tropeçar em algum obstáculo intransponível, a história não se encerra. Os autores não deixam "furos" na sua narrativa, porque o caminho da descoberta é o inverso de seu percurso da criação. O detetive Dr. House não falha. Não porque seja um super-homem, de fato está longe disso, mas porque o seu papel é desmontar o que o roteiro montou para ele e sua equipe. $\mathrm{O}$ autor desmancha o autor. Os autores/roteiristas, através de seu enredo, montam o problema, e, como detetives, decifram o enigma que causou o problema (a doença). Logo, desde que a história policial existe, o detetive é infalível. E se House é um detetive, lhe cabe acertar.

Trabalhando com uma equipe de médicos de várias especialidades, House usa um quadro branco no qual vai escrevendo as possibilidades de diferentes sintomas que poderão ser o prenúncio do diagnóstico. Ele é um homem que trabalha com tentativas e erros, e como na peripécia aristotélica há uma altercação de ações - quando se acha que um sintoma leva a uma doença, outro surge e desfaz-se a hipótese anterior. Ou o outro sintoma se soma e uma doença completamente diferente surge como alternativa. Como chefe da equipe, House é sempre quem tem o insight e descobre o diagnóstico, através das discussões, e dos acontecimentos paralelos surgidos no dia a dia do hospital, ou no cotidiano das personagens.

No entanto, mais do que as de Edgar Allan Poe e Thomas Narcejac, as referências usadas em House MD são as criadas por Conan Doyle e seu detetive Sherlock Holmes. Criado pelo escocês Sir Arthur Conan Doyle (1859-1930), esse detetive foi imortalizado em quatro romances e cinco livros de $\operatorname{contos}^{3}$. Holmes ficou tão famoso que muita gente acredita que ele realmente existiu. No número 221-B da Baker Street, Londres, seu endereço ficcional, até hoje chegam cartas de pedidos de ajuda para desvendamento de crimes e de congratulações pela resolução de crimes. Em House MD, vemos que o número de seu endereço é 221 e na porta de seu apartamento está inscrito "B".

\footnotetext{
${ }^{3}$ Um estudo em vermelho (DOYLE, 1982f), O cão dos Baskervilles (DOYLE, 1982b), O vale do terror (DOYLE, 1982e), O signo dos quatro (DOYLE, 1982c) (romances), Aventuras de Sherlock Holmes (DOYLE, 1982a), Histórias de Sherlock Holmes (DOYLE, 1981b), A volta de Sherlock Holmes (DOYLE, 1981a), Memórias de Sherlock Holmes (DOYLE, 1981c), O último adeus de Sherlock Holmes (DOYLE, 1982 d) (livros de contos).

Dispositiva

v. $1 \mathrm{n} .2$

nov.2012 / abr.2013
} 
Sir Arthur Conan Doyle foi um mestre do romance policial maquiavélico ${ }^{4}$, utilizando-se, além da técnica dedutiva do Dupin de Poe, de métodos científicos mais aperfeiçoados. Como se sabe, Sir Arthur era médico oftalmologista, daí grande conhecedor da medicina legal. House é médico especialista em infectologia e nefrologia, além de expert em elaborar diagnósticos diferenciais.

Conan Doyle criou seu detetive, Sherlock Holmes, baseando-se em um seu antigo professor de medicina, Joseph Bell. Esse médico era reconhecido pela segurança de seus diagnósticos, e diagnósticos são feitos através da leitura de sintomas. Doyle transformou essa leitura de diagnósticos num exercício cativante de dedução para a construção de suas novelas, contos e romances. A poeira marrom nos sapatos, a roupa suja de lama - detalhes que eram sintomas - transformaram-se em indícios, que ajudaram Holmes a desvendar mistérios. House é puro Holmes. Além da leitura corporal de pacientes, dos médicos de sua equipe, das pistas que cada um deles traz, House os conduz em um jogo de arrogância e pseudo-onipotência. Nada lhe escapa.

Vemos a referência explícita a Joe Bell no episódio 11, Alegria ao mundo, da $5^{\text {a }}$ temporada: House ganha um presente de natal, o qual não desembrulha e joga-o fora. Kutner, um dos seus assistentes, o tira do lixo e o desembrulha: Manual de operações de Cirurgia, de Joseph Bell, um livro caro e raríssimo. No desenrolar do episódio, Wilson inventa uma história, para tripudiar com Kutner, diz que o livro foi dado a House por uma antiga paciente por quem ele se apaixonou e que o abandonou, Irene Adler. Aí estão duas pistas - o livro que existe realmente e uma personagem de um dos contos de Doyle, no qual Sherlock apresenta um sentimento amoroso, Um escândalo na Boêmia. (DOYLE, 1982a, p.7/31)

Segundo Álvaro N. de Souza, em As Duas Faces de Apolo (2007)

Sherlock Holmes foi o próprio professor de medicina de Doyle, Joseph Bell, descendente de uma família de médicos em Edimburgo (...). Ele costumava exortar seus estudantes a usarem os olhos, os ouvidos, o cérebro, o instinto de percepção e poder de dedução. No desenvolvimento do personagem, Doyle escreveu: Eu pensava no meu velho professor Joe Bell... no seu poder de detectar os detalhes. Comentando sobre Doyle, o professor Joseph Bell, que o considerava um de seus melhores alunos, disse: Ele era extremamente

\footnotetext{
" O termo "maquiavélico" virou sinônimo de "procedimento ardiloso, velhaco, traiçoeiro", traindo a teoria original de Niccollò Macchiavelli (1469-1527), dito Maquiavel. E é com esse significado que a expressão é usada por Pierre Boileau e Thomas Narcejac - e por mim, reproduzindo-os -, para designar condutas desleais, pérfidas, velhacas que se valem de astúcia e falsidade.
} 
interessado em qualquer coisa relacionada a diagnóstico, nunca se cansava de procurar todos os pequenos detalhes... (SOUZA, 2007).

Podemos ver nos romances e contos de Doyle que o criminoso é caça que ataca, manobrando o inimigo, maquiando o crime e seu cenário, deixando indícios falsos e, muitas vezes, aniquilando testemunhas. Esses crimes são preparados metódica e cientificamente - diferentemente daqueles descobertos pelo detetive de Poe. Na série analisada, a doença ataca, mascarando os sintomas, que muitas vezes mascara outros sintomas, deixando pistas distintas ou erradas e algumas vezes sacrificando doentes em favor de outros - que só assim terão seus diagnósticos completados, tudo para um bem maior, a ciência. "As melhores doenças são como mágicos: chamam a atenção para um ponto do corpo, enquanto o verdadeiro truque está acontecendo em outro lugar”, diz Lisa Sanders. (NADALE, 2009. p.81).

House acredita que "todos os homens mentem", por isso só lhe interessam os sintomas, os quais podem ser analisados apenas pela luz da lógica. O paciente é apenas o objeto de estudo, apenas um caso, cujo diagnóstico deverá ser desvendado, como se desvenda um crime. E como no romance policial maquiavélico há a lógica do criminoso contrapondo-se à lógica do detetive. Se a lógica do detetive é capaz de desmontar a maquinação, o raciocínio do criminoso é capaz de forjar "o crime perfeito". De fato, “quase perfeito", porque perfeito é seu desmontar pelo protagonista.

Em House MD a obviedade em colocar o nome de seu maior interlocutor como James Wilson, oncologista, reforça a referência à personagem Sherlock Holmes. O Dr. John H. Watson, médico, ex-oficial do Exército Britânico, é a personagem memorialista de Holmes, criada por Doyle. Como parceiro de Holmes serve de interlocutor na resolução de seus casos.

É em Um estudo em vermelho que somos apresentados ao detetive e ao seu companheiro, Dr. Watson, o narrador, que narra sua própria história e seu encontro com Holmes.

No ano de 1878 formei-me em medicina pela Universidade de Londres e logo parti para Netley a fim de seguir o curso exigido aos médicos militares. Terminados os meus estudos, fui designado para o Quinto Regimento de Fuzileiros do Northumberland, como cirurgião assistente. (DOYLE, 1982f, p.1112) 
Em Londres, ao procurar um lugar para morar encontra um ex-assistente que lhe fala de um amigo que também procura cômodo para alugar.

- Um sujeito que trabalha no laboratório químico do hospital. Estava a queixarse, ainda esta manhã, porque não podia encontrar com quem dividir o aluguel de uns ótimos cômodos que tinha descoberto, mas eram demasiado caros para a sua bolsa.

- Magnífico! Exclamei. ...

—Você ainda não conhece Sherlock Holmes, disse ele. - Não sei se lhe agradará como companheiro permanente.

- Por quê? Haverá algo que não o recomende?

— Oh! Eu não disse tal coisa. Ele é um tanto esquisito... tem paixão por certos ramos da ciência. Que eu saiba, é uma pessoa muito correta.

- Estudante de medicina?

- Não. E não tenho a menor idéia sobre a carreira que ele pretende seguir. Acho que entende muito de anatomia, e é um químico de primeira ordem. Mas, ao que me consta, nunca fez um curso sistemático de medicina. Estuda sem método, de uma maneira excêntrica, e já acumulou uma série de conhecimentos desusados que espantariam os seus professores. ...

— ... Ele não é dado a confidências, embora seja bastante comunicativo quando lhe dá na telha. ...

-... Holmes talvez seja demasiado científico para o meu gosto... quase cruelmente científico. Posso até imaginá-lo capaz de administrar a um amigo uma pitada do último alcalóide vegetal, não por malvadeza, compreenda-me, mas simplesmente por espírito de pesquisa e para ter uma idéia precisa dos efeitos. Faço-lhe, porém, a justiça de admitir que ele próprio a tomaria com a mesma desenvoltura. Ao que me parece, a sua paixão é o conhecimento exato e completo. (DOYLE, 1982f, p.13-15)

É visto que Sherlock Holmes não é médico, mas um autodidata brilhante e capaz de experiências audaciosas, capaz de tentar se matar se necessário, experiência que ocorre em House MD no episódio 3, 97 segundos, da quarta temporada, que, para provar que não existe nada após a morte, enfia um canivete na tomada, o que lhe causa uma parada cardíaca. Isso porque um paciente quer repetir o acidente que lhe tirou a vida por 97 segundos, e que para ele foram os momentos mais felizes. Nos episódios 15 e 16, A cabeça de House e $O$ coração de Wilson, da mesma temporada, House toma fisostigmina, uma droga alucinógena para tratamento do mal de Alzheimer, que o leva a visões do que pode ter ocorrido - tentar relembrar um acidente em que se envolveu e alguém morreu. Essa droga leva-o a um infarto. A seguir, como as informações ainda não se completaram, concorda em se deixar levar por um procedimento neurológico, que também quase o mata.

Também como Holmes, House é um homem que se droga, o que progressivamente vai lhe deteriorar física e mentalmente. Viciado em Vicodin - um derivado do ópio, usado também para manufaturar a heroína, é um dos medicamentos mais poderosos. Vicodin 
diminui com sucesso a dor, mas é altamente viciante, e quando se faz uma desintoxicação deste remédio, a dor sentida é a mesma da que, a princípio, foi retirada pelo remédio. Como já foi dito, House sente uma dor intensa cotidianamente e acredita que a dor física o faz insensível às dores dos pacientes e a droga o faz melhor na busca do diagnóstico. Durante os quarenta e poucos minutos de cada episódio, House toma um número incontável dessas pílulas, na frente dos colegas, em casa ou nas consultas aos pacientes.

Holmes usava a heroína como fonte de inspiração. Em $O$ signo dos quatro, de Conan Doyle, há uma cena similar, relatada por Watson, médico:

Sherlock Holmes tomou o frasco que estava sobre a borda da lareira e, abrindo um elegante estojo de marroquim, tirou a sua seringa hipodérmica. Com os dedos brancos e nervosos, ajustou a agulha delgada e arregaçou o punho da camisa. Durante um momento pousou o olhar no pulso e no antebraço vigoroso, pontilhado de inúmeras picadas. Finalmente, espetou a ponta aguda, comprimiu o êmbolo, e reclinou-se na sua poltrona forrada de veludo com um longo suspiro de satisfação.

Havia muitos meses que eu testemunhava aquela operação três vezes por dia, mas nem por hábito pudera reconciliar-me com ela. ... Perdi a paciência.

- Que é hoje? Perguntei. - Cocaína ou morfina? ...

- Cocaína, respondeu. ... Quer experimentar um pouco? (DOYLE, 1982c, p.7,8)

O diálogo continua, com o médico, Watson tentando lhe convencer dos perigos das drogas.

- Mas reflita! Ponderei com gravidade. - Avalie o que isso lhe custa! O seu cérebro poderá excitar-se, despertar, como me diz, mas isso é um processo mórbido, patológico, que implica invalidá-lo para sempre. Lembre-se que não falo apenas como de um camarada para outro, mas como médico até certo ponto responsável por sua saúde. (DOYLE, 1982c, p.8).

Durante o seriado, em vários episódios, House tenta se desintoxicar - o que culmina com sua ida para uma clínica de recuperação no último episódio da quinta temporada, ao som de As tears go by, dos Rolling Stones. A sexta temporada, inclusive, tem seus primeiros episódios passados em uma instituição de reabilitação, ou melhor, em um hospital psiquiátrico.

A música é fundamental nos seriados norte-americanos e em House MD ela é presente nas referências tanto pop como The Who, Talking Heads, Radiohead e outros, quanto em standards como Cole Porter, até em clássicos como Schumann e Beethoven. Muitas dessas são executadas pelo próprio protagonista, o que também liga House a Holmes. O médico é exímio pianista, guitarrista, violonista e tocador de gaitas, o que faz 
quando resolve um caso ou está na fase de incubação criativa. Sherlock Holmes era um violinista que passava horas a tocar, enquanto elucubrava a solução sobre seus casos. Nas madrugadas em que tentava decifrar os crimes, Watson era incomodado pela vibração do violino, não por ser mal tocado, mas pelo horário inconveniente.

Wilson é um Watson mais crítico, superego de House. Amigo leal serve também como sua consciência, criticando-o e às vezes tentando impedi-lo de satisfazer plenamente os seus instintos e desejos absurdos. É a repressão, mesmo gentil e cordato. Manifesta-se indiretamente, como um conjunto de interdições e deveres, e, por meio da amizade, pela produção do "eu ideal”, isto é, da pessoa moral, boa e virtuosa. No episódio 8, da quarta temporada, diz a House: "Claro que seu sangue é AB, recebe de todo mundo". House retruca: "E você é O, doador universal".

House acabou. Durante oito temporadas o médico responsável por diagnosticar o que ninguém conseguia foi libertado da sua sina. Como em Easy Rider (Sem Destino, 1969) - road movie americano de 1969, escrito por Peter Fonda, Dennis Hopper e Terry Southern, produzido por Fonda e dirigido por Hopper - Gregory House e James Wilson partem sem destino em suas motocicletas, à espera da morte iminente do segundo. House ironicamente vira um doador ao se fazer de morto para poder acompanhar o companheiro, o qual se transforma em receptor de uma amizade ilimitada.

No entanto, nada é tão óbvio quanto no filme original, no qual as personagens Wyatt e Billy viajam sem destino para alcançarem a liberdade pessoal, mas as referências à dupla de motoqueiros são evidentes. Se no filme original discutiam-se os assuntos sociais, a ascensão e queda do movimento hippie, as tensões da América da década de 1960, a série House MD discutiu as doenças do século XXI como metonímia da patologia universal.

House é uma personagem contemporânea, é um herói trágico e um anti-herói, dependendo da visão e da simpatia do espectador. Ele vicia. Não há como não se apaixonar pelo protagonista e pelo seu discurso politicamente incorreto que se torna cada vez melhor pela qualidade dos roteiros.

House $M D$ é um dos produtos televisivos que fazem o cinema se render à televisão e com que os seriados ganhem cada vez mais destaque e público cativo. E é notório de onde David Shore e seus roteiristas nos trouxeram Dr. House - bebendo nas águas da 
literatura do século XIX, decalcando-o do Dupin de Poe e do Holmes de Doyle e o modernizando. Shore forjou sua morte no último episódio, assim como Doyle matou Sherlock no conto "O problema final" e o ressuscitou devido a manifestações de dor e cólera dos leitores.

O homem é animal racional, repartido entre a sensibilidade e o inteligível. É sua vocação traduzir o sensível em inteligível, com grande ou pequena dificuldade, e, às vezes, à custa de muitos erros. É o que o seriado House $M D$ prega e que nos vicia.

Talvez essa seja a gesta das histórias policiais. E apesar de parecer que a narrativa policial constituiu-se, pouco a pouco, em uma época recente, isso é apenas aparência. Os mecanismos da razão que ela emprega são contemporâneos do próprio homem, ela já é atávica ao próprio espírito humano.

A trama policial é uma ficção, um jogo de imaginação em que a razão é utilizada

como processo fundamental. É o entretenimento, tomando emprestado o modelo da investigação científica. Na narrativa policial há teoria e pesquisa. Há hipótese e indução, para chegar-se a um resultado lógico, através da dedução. O cientista transforma-se em detetive, as pistas são calcadas em teorias e, assim, o crime vira objeto de prazer para leitores que, a partir dele, seguirão indícios até a resolução final. O criminoso, a vítima, a lógica da investigação, tudo está implícito na razão usada para compreender as coisas.

Puro entretenimento, agora transformado em seriado televisivo. No mínimo.

\section{Referências}

DOYLE, Conan. A volta de Sherlock Holmes. São Paulo: Melhoramentos, 1981a.

DOYLE, Conan. Histórias de Sherlock Holmes. São Paulo: Melhoramentos, 1981 b.

DOYLE, Conan. Aventuras de Sherlock Holmes. São Paulo: Melhoramentos, 1982a.

DOYLE, Conan. O cão dos Baskervilles. São Paulo: Melhoramentos, 1982 b.

DOYLE, Conan. O signo dos quatro. São Paulo: Melhoramentos, 1982c. 
DOYLE, Conan. O último adeus de Sherlock Holmes. São Paulo: Melhoramentos, 1982d.

DOYLE, Conan. O vale do terror. São Paulo: Melhoramentos, 1982e.

DOYLE, Conan. Um estudo em vermelho. São Paulo: Melhoramentos, 1982f.

ECO, Umberto. Sobre os espelhos e outros ensaios. Rio de Janeiro: Nova Fronteira, 1989.

IRWIN, William e JACOBY, Henry. House e a filosofia: todo mundo mente. São Paulo: Madras Editora, 2009.

HOLTZ, Andrew. A ciência médica de House: a verdade por trás dos diagnósticos da série de TV. Rio de Janeiro: Editora Best seller, 2008.

MACHADO, Arlindo. A televisão levada a sério. São Paulo: Editora SENAC, 2000.

NARCEJAC, Thomas. "Le roman policier". In GUBERN, Román (org.). La novela criminal. $2^{a}$ ed., Barcelona: Tusquets Editores, 1982. p. 49-80.

NADALE, Marcel. “As mentes de House". In Superinteressante, São Paulo: Abril, Novembro, 2009, Ano 2, edição 271, p. 79-83.

NÖTH, Winfried. Panorama da semiótica. São Paulo: Annablume Editora, 2003.

POE, Edgar Allan. Ficção completa, poesia \& ensaios. Rio de Janeiro: Editora Nova Aguilar, 1997.

SOUZA, Álvaro N. de. As Duas Faces de Apolo. Salvador, Bahia: Editora Casa da qualidade, 2007. Disponível em: <http://www.traca.com.br/livro/148115/as-duas-faces-deapolo > Acesso em: 6 de fev. 2010.

TODOROV, Tzvetan. “Typologie du roman policier”. In TODOROV, Tzvetan. Poétique de la prose: choix, suivi de nouvelles recherches sur la récit. Paris: Éditions du Seuil, 1978. p. 9-19.

Recebido em : 07/07/2012

Aprovado em: 17/09/2012

Dispositiva

v. 1 n. 2

nov.2012 / abr.2013 